\title{
Malignant Esophageal Neoplasm
}

National Cancer Institute

\section{Source}

National Cancer Institute. Malignant Esophageal Neoplasm. NCI Thesaurus. Code C7478.

A primary or metastatic malignant neoplasm involving the esophagus. 